\title{
Linaje, territorio e imagen en Ramal de Cynthia Rimsky
}

Lineage, territory and image in Ramal by Cynthia Rimsky

\section{Daniela Alcívar Bellolio}

Universidad de Buenos Aires

DOI: https://doi.org/10.32719/13900102.2018.44.7

Fecha de recepción: 19 febrero 2018

Fecha de aceptación: 23 abril 2018 


\section{RESUMEN}

El trabajo examina la novela Ramal (2011) de Cynthia Rimsky en busca de las particulares relaciones presentes entre espacio e imagen. Se analizan, por un lado, las características materiales de las imágenes fotográficas de la novela para comprender cómo dialogan con e intervienen en la configuración de la narración verbal y sus particulares tonos y operaciones de mostración e invisibilización. Por otro, se piensa el paisaje en tanto que dispositivo fundamental para la política narrativa de la novela. La articulación que estos dos dispositivos elaboran para generar una caracterización, ambigua y problemática, de la genealogía del protagonista es el objeto principal del presente artículo. Palabras clave: Chile, Cynthia Rimsky, paisaje, imagen, linaje, narrativa.

\section{ABSTRACT}

This paper analyzes the novel Ramal (2011), by Cynthia Rimsky, searching for the particular relationships between space and image. On the one hand, the material characteristics of photographic images in the novel are analyzed to understand how they dialogue with, and intervene in, the configuration of the verbal narration and its particular tones and operations of display and invisibility. On the other hand, landscape is thought of as a fundamental device for the narrative policy of the novel. The main object of this article is the articulation developed by these two devices in order to generate an ambiguous and problematic characterization of the protagonist's genealogy.

KEYWORDS: Chile, Cynthia Rimsky, landscape, image, lineage, narrative.

\section{UNA CALIGRAFÍA AUSTERA}

El Ramal de tren Talca-Constitución, en la VII región de Chile, está desde hace años al borde de la extinción. Distintos proyectos turísticos han procurado, sin éxito, revivirlo, y con él a las poblaciones que se fueron creando alrededor de sus estaciones en tiempos más prósperos. De las antiguas estaciones no queda más que un par de paraderos distinguibles únicamente por chozas abandonadas o por vagones en desuso que quedaron ahí para refugiar a los eventuales pasajeros mientras esperan a que pase el tren. En el año 2007 se elevó este último ramal de la Empresa de Ferrocarriles del Estado a la categoría de Monumento Nacional de Chile, con el fin de impedir que se levanten las vías, por lo que el tren sigue bordeando el río Maule, todos los días a las siete de la mañana y a las cuatro de la tarde, con sus escasos pasajeros, generalmente obreros o comerciantes de las empobrecidas poblaciones que sobreviven entre Talca y Constitución, que viajan hasta alguno de esos dos polos para conseguir sustento. La dirección de este ramal tenía en principio el destino de acercar a los trabajadores a 
la planta de celulosa construida en Constitución, a la que los campesinos vendieron sus tierras. Una vez devastada la zona por la contaminación que la planta provocó, que los dejó sin tierras, sin pasto, sin aguas y sin vegetación comestible, las poblaciones del ramal quedaron desamparadas del estado, del turismo que nunca llegó y de cualquier otro tipo de ayuda.

El protagonista de Ramal (Rimsky 2011), cuyos antepasados nacieron en esa zona y lograron huir a Santiago, tiene como encargo revivir el ramal con un proyecto turístico, y con tal objetivo viaja desde la capital para visitar y explorar el tramo y encontrar sus potencialidades. Casi siempre llamado "el que viene de afuera", sin nombre propio, el personaje aparece en la novela como un sujeto borroso, ajeno a los atributos; su naturaleza se va configurando por los objetos que observa, por el lugar del que viene o donde se encuentra. Si bien, como en el resto de novelas de Cynthia Rimsky, el del linaje es un motivo importante -y continuamente intervenido por la digresión y el viaje-, y en Ramal tendrá una importancia abrupta hacia el final, en principio el protagonista carece de contornos precisos, se configura por lo exterior, por aquello que ve y registra, por el recuerdo del reflejo fragmentado de sus antepasados en el espejo de la casa de la calle Maruri, en el barrio de la Estación Mapocho, y por el modo en que la gente miserable de los pueblitos del ramal lo mira. "El que viene de afuera” es un extranjero entre Talca y Constitución, si bien su familia nació en la zona, es un extranjero en el país europeo donde vivió nueve años, en la casa del barrio Mapocho de la que siempre quiso irse pero a la que nunca pudo dejar de volver, en el barrio alto donde su madre siempre quiso que se quedara. En todos estos ámbitos, su existencia se dibuja débilmente a partir de los reflejos de su padre y abuelo, por el suyo propio, siempre fragmentario, proyectado sobre los paisajes del ramal, y por el mecanismo que habla de él siempre dejándolo fuera: la fotografía.

El modo en que es narrado el trabajo del protagonista de Ramal guarda cierta relación con las formas de la labor etnográfica o incluso antropológica de quien recorre, observa y registra condiciones y formas de vida ajenas con un fin más o menos científico o social. La mirada del personaje sobre las minúsculas comunidades agrupadas alrededor de las estaciones sobrevivientes del ramal que le han encargado salvar mediante un proyecto turístico que lo revalorice se mantiene en un límite, móvil pero explícito, de exterioridad con respecto a lo que ve y a las personas que conoce. Por eso predomina en el lenguaje del narrador un tono descriptivo, 
escueto, generalmente despojado tanto sobre los grados de la miseria que se le presentan al personaje en su recorrido como de sus propias impresiones: un tono de cadencia telegráfica que se articula con la composición anodina de las fotografías del paisaje recorrido, fluctuante entre lo descriptivo y lo abstracto, ajena a cualquier esteticismo pintoresco o sublime.

Este lenguaje escueto del narrador, potenciado y suplementado por la composición de las imágenes fotográficas, conforma un protagonista singular, sin nombre, cuyas características particulares se diluyen en su observación del espacio de lo que ocurre afuera. ${ }^{1}$ Lo que se sabe de él está determinado por las breves descripciones del territorio y sus habitantes que ofrece el narrador, y por la mirada que se manifiesta en las fotografías: la narración habilita la suposición de que el ojo del otro lado del aparato es el del protagonista, en una singular comunión formal con la modulación verbal del relato, como si las imágenes fueran hacia un deseo paradójico de tornarse écfrasis de las palabras que no terminan de configurar al personaje que es su punto de convergencia.

Ahora bien, al registro de lo exterior, a la notación de fenómenos y condiciones, al recuento despojado de testimonios oídos y de dinámicas ajenas en los poblados del ramal, se yuxtaponen los recuerdos y los avatares del linaje de los Bórquez, el pliegue más íntimo de la figura borrosa del protagonista que se permite el relato. Como si el avance descriptivo sobre los paisajes y los personajes, que la lengua del narrador configura como ajenos, habilitara de algún modo el espacio propicio para el advenimiento de un segundo paisaje que se superpone con el primero y que escenifica los movimientos (evadidos, ocultos) de la genealogía del protagonista, la narración decanta de modo moroso desde el amplio espectro de la decadencia

1. Significativamente, la novela solo revela del personaje su apellido, y lo hace a través del recuento de los nombres de su padre y de su abuelo cuando narra el pesado ritual de la entrada de la luz a la casa de Maruri. Esto pone en juego dos elementos fundamentales en Ramal: por un lado, el linaje familiar que constituye el aliento de toda la narración, concentrado en la herencia simbólica de la apertura de las lucernas por la tarde (herencia que se mantuvo vigente hasta el protagonista pero que él no podrá transmitir a su hijo), y por otro, la casa de Maruri como espacio físico y simbólico de la pérdida: la morada que sus antepasados usaron como espacio de transición entre la migración desde Talca (ese oscuro punto perdido en el mapa chileno al que el protagonista es fatalmente devuelto, como un retorno involuntario y trágico a los orígenes) y el barrio alto de Santiago, el escenario vacío donde reposan los reflejos fragmentados de su abuelo y de su padre y que revelará, junto con el suyo propio, en la última línea de la novela, su nombre. 
social y la pobreza territorial hacia el punto más intenso de la tragedia personal. Este movimiento de precipitación de lo general a lo particular y de lo ajeno a lo más propio (de lo descriptible a lo inenarrable) se inscribe de modo explícito en el espacio; es el trayecto del ramal Talca-Constitución, esa línea doblemente marcada, redibujada sobre el plano que abre el libro, intervenida, son los paisajes atravesados fatalmente por esa ruta ferroviaria, el punto en el que se produce el encuentro que da lugar a la novela.

\section{TRAZO, TERRITORIO E IMAGEN}

Lo que abre Ramal son dos paratextos que remiten directamente a la territorialidad en la que se van a poner en juego todos los elementos de la novela: primero, un listado de las características técnicas del Buscarril Talca-Constitución que incluye distancia de recorrido en kilómetros y tiempo, número de estaciones, año de fabricación, cantidad de vagones, velocidad máxima, entre otras. Inmediatamente después, un fragmento del plano vial de una parte de la VII región de Chile que ocupa dos páginas completas. Este plano, cuyos márgenes no han sido determinados bajo un criterio de organicidad ni de rigor geográfico (el plano no muestra la ubicación del territorio seccionado en relación con el resto del país ni expone accidentes topográficos identificables que anclen a quien lo mira en alguna trama espacial reconocible), hace proliferar en la misma medida líneas de diversos tipos (entrecortadas, gruesas, dobles, simples, oscuras o más claras), topónimos y algunos símbolos viales más o menos reconocibles. Sobre el plano, cerca del centro de la imagen completa, una línea hecha a mano con tinta o lápiz que duplica, paralelamente, la línea irregular que representa el trayecto que va desde Talca a Constitución y señala las estaciones sobrevivientes del ramal (que no coinciden con las que indica originalmente el plano) e indica los nombres con los que esas estaciones son conocidas en el tiempo del relato.

En esta yuxtaposición del íncipit se ponen en juego de modo ejemplar esos dos elementos de los que se nutre Ramaly el punto de inflexión que constituye su espacio común: el territorio comprendido entre dos puntos anodinos de la geografía chilena está pautado al mismo tiempo por un lenguaje despojado, cercano al esquema del técnico o a la notación del cientista y por la marca irrepetible, íntima, de una mano que vuelve a dibu- 
jar una línea sobre un mapa, que vuelve a nombrar las marcas toponímicas del documento técnico de acuerdo con los movimientos y las intensidades afectivas de la propia vida. Esas marcas en tinta sobre el plano desmontan el rigor del documento geográfico y descomponen el despojo del tono del relato en la medida en que sugieren una potente precisión de orden afectivo - una suerte de corrección de la realidad- que se irá develando paulatinamente en la narración, entre los distintos momentos del registro verbal y fotográfico de la realidad socio-económica y geográfica de las estaciones del ramal y los poblados que las rodean, hasta decantar en el relato (quizá sería más preciso decir la imagen) del suicidio del hijo del protagonista.

Es esta articulación, pues, lo que da al relato de Ramal su densidad y lo que determina su avance. La particular mudez de las fotografías de espacios y paisajes del libro (la imagen intervenida del plano vial es una excepción significativa) debe ser leída más allá de la evidente función ilustrativa que tienen las imágenes con respecto a las descripciones del narrador: si una primera lectura podría inferir del conjunto de fotografías de la novela un carácter suplementario de descripción, una forma de registro solidaria con el tono informativo del narrador, un examen del conjunto de las fotografías y de los contrapuntos que se generan entre ellas apunta hacia otras direcciones.

Los planos amplios, marcadamente descriptivos de estaciones, paisajes, construcciones en proceso de degradación o de objetos de los que el narrador viene hablando son lo que da la pauta de la mayor parte de las fotografías. Es por esto que el sentido inmediato de esas imágenes se ancla en un espectro testimonial, prueba de registro, herramienta útil a la notación sucinta, al proyecto como borrador, como plan de trabajo a futuro. Ramal podría leerse como un plan, un esquema o un proyecto que no llega nunca a ser realizado. El tono del narrador, el modo en que el protagonista registra lo que ve y su propósito explícito (recoger datos útiles a los fines de generar un proyecto turístico para el Servicio Nacional de Turismo que reviva el último ramal en funcionamiento del país), hace de la novela un relato de apuntes y esquemas, de notas y, en ese sentido las fotografías cumplirían una función documental. Es la intrusión arbitraria de las imágenes del linaje familiar del protagonista, la presión que estas ejercen sobre ese registro lacónico, lo que desvía al relato de su matriz primaria de proyecto o plan. A esas imágenes sin pretensiones estéticas, que aparentan un registro plano, funcional a algo que está por fuera de ellas, el agregado 
de la inflexión personal que se cuela lentamente en la narración le suma un suplemento de sentido que reenvía a ellas y opera una resignificación de su registro documental.

La naturaleza ambigua de la fotografía entendida como índice, huella que depende ineluctablemente de la cercanía física, de la contigüidad, puede ayudar a habilitar la emergencia de un sentido de las imágenes de Ramal por fuera de su valor ilustrativo. Ya Walter Benjamin enfatizaba el contingente de aqui y ahora que permanecía como sustrato material de la imagen fotográfica, acentuando de este modo no tanto la realidad ni los artificios propios del mecanismo fotográfico como el agenciamiento que se registraba de modo instantáneo en un instante preciso para "quemar" el carácter de la imagen y expresar cierto tipo de verdad. ${ }^{2}$ En virtud de la radical "copresencia” que concentra la imagen fotográfica, el análisis se centraría, según Roland Barthes, en el espacio fijo de la imagen en la que todo viene dado, espacio "indesarrollable de una inmovilidad viviente" que la hace similar al haikú y que es solidaria con el núcleo conceptual de la imagen como "sustrato indecible" (Barthes 2005, 78, 87). Es decir que el estudio de la imagen fotográfica, desde la perspectiva del signo indicial, puede estimular un análisis que deslice el foco de los objetos individuales (imágenes y textos, personajes y paisajes) al agenciamiento que se produce entre elementos contiguos y heterogéneos para examinar las formas que aparecen en esas articulaciones específicas en el relato.

En este mismo sentido, pues adopta como base metodológica la naturaleza indicial del signo fotográfico desarrollado por Benjamin y posteriormente por Barthes, Rosalind Krauss ha pensado lo fotográfico en su capacidad de producir un deslizamiento epistemológico que puede resul-

2. (Benjamin, 2015b). Este podría considerarse el enunciado base de la perspectiva que entiende a la fotografía como un signo deíctico -o índex, en contraposición a las primeras posturas que la pensaban como reflejo de la realidad o de aquellas, de corte estructuralista, que la configuraban como suerte de lenguaje capaz de transformar la realidad. También para André Bazin (2008) la capacidad mimética no era más que una característica más, e incluso secundaria, de la fotografía. Su ontología estaba en su "génesis automática" (28) y, así también, en la relación de contigüidad entre la imagen y el referente, en su principio primordial de transferencia. Este desplazamiento propio del signo deíctico o índice habilita un deslizamiento teórico que deslinda el foco de una esencia fotográfica para pensar la relación de la huella con el significado y lo que esa condición de cercanía implica y revela (Krauss 2002, 16), otorgando una densidad conceptual propia a la contigüidad como dispositivo teórico y narrativo. 
tar especialmente útil para esta lectura de las fotografías en Ramal. Este desplazamiento haría de la fotografía ya no un objeto de investigación (en cuya materialidad se centrarían los esfuerzos hermenéuticos y conceptuales), sino un objeto teórico, "una especie de casillas o filtro mediante el cual es posible organizar los datos de otro campo que se halla con relación a él en una posición secundaria" (Krauss 2002, 14). La fotografía como “mancha ciega" (Krauss 2002, 14), centro móvil sobre el que, en rigor, no puede decirse nada, pero que reenvía a objetos heterogéneos con líneas de fuga de características singulares.

La acumulación de fotografías anodinas de los lugares que describe la narración genera un verosímil descriptivo-geográfico que encuentra su punto de quiebre en la secuencia fotográfica que le sigue al relato del suicidio del hijo. La novela inicia con una descripción minuciosa de un ritual familiar: la apertura de las lucernas con ayuda de un madero en la casa de la calle Maruri del barrio Mapocho. Ritual que figura un linaje marcado por movimientos taciturnos, los sujetos que lo realizan aparecen ajenos, apegados a un espacio decadente, donde los objetos reposan más allá de quienes los usen. Casa siempre a medio abandonar, la de Maruri es el primer escenario que, en tanto que espacio, cumple un papel decisivo en las vidas de los Bórquez: el sillón de dos cuerpos sobre el que se recuestan, con las piernas encogidas, el padre y el abuelo del protagonista y, al final, él mismo (pero no su hijo, pues ha muerto), está frente a un espejo que los refleja parcialmente.

La descripción recurrente de este reflejo, que se liga insistentemente a la descripción de la casa oscura, usada por los hombres de la familia como consultorio odontológico y como taller después, irrumpe en el relato del viaje del protagonista por el ramal como una imagen relampagueante. Los conflictos velados que habitan esta casa se manifiestan en principio de modo negativo: el barrio Mapocho es el lugar al que los Bórquez logran llegar tras huir de la provincia (la VII región), una especie de refugio que, sin embargo, no se abandona para continuar la marcha. Cuando el padre del protagonista logra comprar una casa en el barrio alto de Santiago, establece en la casa de Maruri su consultorio, a pesar de los deseos de su esposa. Más tarde, el protagonista establece ahí su taller y domicilio, y su hijo, que vive en Talca con su madre, debe visitarlo dos veces por mes por orden del Juez de Familia. El hijo siente un rechazo fuerte por la casa de Maruri y por su padre, y a través de las escasas menciones a esto se pre- 
figura en la novela el advenimiento de la desgracia, de la que no sabremos sino hacia el final del libro:

La primera vez que su padre le permitió coger el madero, le fue imposible equilibrarlo y más difícil todavía dirigirlo con pericia hacia la lucerna. Desconoce cómo se habrá comportado el madero al desaparecer de Maruri el abuelo Arnoldo. Al morir su padre, el madero no volvió a titubear en sus manos. El nacimiento de su primer hijo lo llevó a pensar que un día él también querría abrir y cerrar las lucernas con el madero, pero a su hijo le disgusta la habitación que sirvió de consulta dental a Salomón Bórquez y de taller a él. Si no existiera el dictamen del Tribunal de Familia que lo obliga a dejar la casa de su madre, con la que vive en Talca, para visitarlo a él dos veces al mes, durante tres días en la casa de Maruri, su hijo se hubiese mantenido alejado de la estación de trenes y de lo que allí ocurrió (Rimsky, 18).

La angustia del hijo se acentúa hasta el paroxismo en el día de su suicidio, dejando de manifiesto el carácter espacial que la tiñe. Un día, por equivocación, en lugar de tomar el colectivo que lo llevará a su escuela toma otro, que lo lleva a Colín, el paradero miserable que queda a 8 kilómetros de Talca. El niño permanece inmóvil durante nueve horas en Colín, ese territorio devastado y abandonado, y ese tiempo se convierte en distancia infinita para él: "En diez minutos, veinte si se atrasa, el hijo habrá cumplido nueve horas lejos de su casa. Ha llegado con sus pensamientos más lejos que nunca del hogar. Sería una traición que habiendo llegado tan lejos con su pensamiento ahora niegue su pensamiento y viva fingiendo que no llegó a pensar" (149).

Es la distancia del hogar lo que revela el "agujero que anidaba en su pecho" hasta el punto de hacer imposible la vuelta atrás. De este modo, la desgracia encuentra su modo de manifestarse a través de la relación de los personajes con el espacio. El protagonista vuelve a la casa de Maruri después de nueve años de vivir en Europa, tras la muerte del hijo, y recorre el ramal en busca de algo, pero ese algo siempre se le escapa, "está más allá de él" (123). De alguna de esas poblaciones en el trayecto empobrecido entre Talca y Constitución salió su familia y allá concluyó de modo violento ese mismo linaje. Su recorrido por el ramal, si bien se resignifica a partir del relato de la muerte del hijo, estuvo desde el principio atravesado intermitentemente por la historia familiar, como un sino: de hecho, la única razón por la que le asignan el proyecto turístico para el ramal, fallido de antemano, aun sin poseer aptitud alguna para llevarlo a cabo, es que su 
abuelo nació allí, por lo que el desinteresado funcionario que lo contrata concluye que "lo lleva en la sangre" (Rimsky, 19).

Entonces, el conjunto de fotografías descriptivas de los poblados del ramal, mudas en su composición indiferente y despojada, construyen el entramado verosímil del registro de una geografía afectiva, del territorio de los orígenes y de los finales, el espacio, también, de un forzoso, lacerante recomienzo. Este entramado entra en crisis por la misma materialidad de la imagen cuando finalmente el relato decanta en el suicidio del hijo en Colín, ese paradero del que se nos había hablado al inicio con una línea lacónica y una fotografía.

\section{EXCURSO. TRES FOTOGRAFÍAS Y UNA MUERTE: CÓMO LEER UNA ESCENA IMPOSIBLE}

Nadie experimenta la muerte. La distinción que precisa Vladimir Jankélévitch entre misterio y secreto, para referirse a la muerte, pasa por la constitutiva in-significancia del primero en contraste con el ocultamiento de algo valioso, lleno de sentido, que implica el segundo. La muerte sería, en efecto, un misterio sin secreto; lo que ha de llegar sin falta a cada uno, lo que ocurre todos los días en todas partes y que hoy es banalizado y viralizado compulsivamente por los medios de comunicación pero que, a pesar de todo, conserva un fondo de diáfana inaccesibilidad.

Hay -dice Jankélévitch- un misterio de la muerte, pero ese misterio se caracteriza por el hecho de que no es un secreto [...]. No hay secreto y es en eso que la muerte es un misterio. Es decir que es un misterio a pleno día, a plena luz, como el misterio de la inocencia. Es un misterio que está en la transparencia, en el hecho mismo de la existencia [...]. Un secreto se descubre, pero un misterio se revela y es imposible descubrirlo (Jankélévitch 2004, 35).

Lo oculto del secreto supone aún un posible movimiento de la voluntad, la posibilidad de una búsqueda que brinde respuestas, la promesa de un descubrimiento. Lo que aparece simplemente, "a pleno día”, en su abierta superficie ajena al significado, neutraliza la voluntad porque no la implica ni la necesita. La muerte sería un misterio con el que vivimos, coti- 
diano. En la medida en que revela la falta de sentido de la vida (ya que va a terminar, ya que todos los trabajos y los esfuerzos humanos por constituir una conciencia y un proyecto terminan invariablemente en la suspensión del ser), en esa medida, pues, la muerte puede ponernos en contacto con la impersonalidad constitutiva que obliteramos para poder vivir: la que a veces se revela en los sueños o en los recuerdos y que pone en evidencia que existe un fondo de vida, unos fragmentos de mundo, que no dependen de ni se deben a la conciencia. En esas intrusiones involuntarias que nos constituyen pero que no dominamos, varios han visto una cifra de la muerte: algo que ocurre en nosotros, el más íntimo y el más certero de los acontecimientos que nos acaecerán, pero del cual estamos ausentes. La ocurrencia en nosotros, pero sin nosotros, de algo inaudito.

La fotografía es huella de ausencia. Según la conocida fórmula benjaminiana, el aura es "el aparecimiento único de una lejanía, por cercana que pueda estar" (Benjamin 2015a, 31). La fotografía testimonia la existencia real de algo o alguien en un instante singular, que existió una vez y nunca más. Su carácter específico es el ser indicio y no ícono ni símbolo. Su figura es la metonomia y no la metáfora; su poder, el de la irradiación y no el de la mímesis. Lo que esto implica es ante todo una potencia que surge de la contigüidad, de la cercanía imprescindible entre la cámara y el objeto fotografiado en el momento de la toma, la prueba sin restos de una presencia, por enigmática que sea, ante nuestros ojos. Esta prueba de existencia puede carecer de significado, pues la imagen, extraída de una cadena de imágenes que figuren una sucesión temporal llena de sentido, aparece como pura singularidad, inmune a los universales. ${ }^{3}$

3. En este sentido es particularmente útil la perspectiva que aporta José Luis Pardo sobre el espacio en tanto que imagen ajena al sentido. La relación entre el espacio como imagen detenida y el tiempo como sucesión sería desarticulable si se problematiza la naturaleza y posibilidad del nexo entre ambos (Pardo 1991, 18). La hipótesis fundamental que genera el sintagma imagen-espacio permitiría llevar a cabo este ejercicio de imaginación teórica cuya premisa es que los espacios, en sí mismos, son exteriores al sentido y que, si lograran sustraerse del tiempo como único factor que genera un nexo entre una imagen y otra (entre un espacio y otro) para otorgarles determinada función y significado dentro de una sucesión, permanecería exterior la narración, a la diacronía y por tanto al sentido. El objetivo es desnaturalizar momentáneamente la relación directa entre tiempo y espacio para imaginar un vacío temporal en el que los espacios como mónadas de percepción pura puedan permanecer ajenas a cualquier relato; es decir, para examinar las posibilidades de un espacio puro, de una pura imagen, que pueden ser parte de una cadena de compuestos pero no contienen, en sí mismas, componente 
Su contundencia, sin embargo, es innegable: el "esto ha sido" barthesiano revela otro misterio sin secreto, el de la existencia muda de los rostros y de los espacios cuando no son -no pueden ser- explicados ni asimilados, cuando fulguran en un único instante singular, el inconsciente óptico, para insistir en Benjamin, que se revela por la fotografía y que queda petrificado en esa imagen sin anclaje de sentido.

El suicidio de un niño no puede significar. "El aire que el tren despide a su paso atraviesa el pecho del hijo. Un frío como nunca antes sintió lacera los bordes del agujero. El hijo baja de la plataforma y coloca un pie en cada riel sin bajar los brazos. Solo un dolor más fuerte podrá aplacar ese dolor innombrable, piensa el hijo arrojándose contra su reflejo": (Rimsky, 152) en Ramal, hacia el final de la historia de una línea de trenes semi abandonada que fue cifra de proyectos y aspiraciones de prosperidad y termina siendo línea discontinua, cortada, tachada, que dibuja un trayecto de miseria que persevera en la agonía porque dejarse morir no es una posibilidad, hacia el final de esta historia de trenes y pueblos, pues, un niño se suicida. Tras tomar el colectivo en la dirección equivocada y llegar a un pueblo cercano en el que pasa nueve horas solo, a metros apenas de la parada del colectivo que puede devolverlo al hogar, se atraviesa, de frente y con los brazos abiertos, a un tren en movimiento.

Los acontecimientos que decantan en el suicidio infantil no tienen relevancia: la vaga tristeza de la línea genealógica de la que el niño es el último eslabón no alcanza para justificar el suicidio. Asimismo, del extravío, el narrador nos hace saber que el camino de vuelta a casa estuvo siempre

alguno. En el campo de la teoría fotográfica y cinematográfica pueden encontrarse desarrollos particularmente útiles en este sentido plástico y deconstructivo del significado de las imágenes (Pardo 1991).

En esta línea de análisis, la experiencia estaría compuesta de átomos de sensación que existen independientes unos de otros, y el nexo entre ellos no existe, o existe como mentira que obliga a las imágenes a insertarse en una sucesión que les es completamente ajena. Véase (Wenders 1988). Sin la presencia regidora del tiempo que habilita la noción misma de repetición, cada imagen-espacio sería única, irreductible a cualquier sucesión y a cualquier historia. Otro modo en que se ha entendido y descripto esta naturaleza asignificante de la imagen desde la teoría es la caracterización de las situaciones ópticas y sonoras puras -(Deleuze 2005, 33)- en el cine italiano de la segunda posguerra, aquellas que dan cuenta de un estado mental de los personajes cuyos lazos sensoriomotrices han sido rotos y que, por tanto, no pueden reaccionar según estímulos comunes, inducen una comprensión de la imagen por fuera de la sucesión y de la asignación de significados. 
cerca, al alcance del niño. Es violenta la constatación de la intemperie constitutiva que lleva al niño a echarse a las vías, es definitiva, es irreversible, pero para ella la novela no ensaya razones, sentidos ni justificaciones, apenas la constatación de un linaje que se movió siempre entre los límites de ese ramal moribundo.

Tras el relato de la muerte del niño, tras la inevitable elipsis que es el relato de su suicidio, hay tres fotos, cada una en una página. Las tres fotos han sido tomadas desde el interior de un tren, a través de una de las ventanillas. Los vidrios han sido rayados insistentemente con algún objeto filoso. Del otro lado del vidrio se extiende un paisaje anodino. La primera fotografía muestra ese paisaje desde el tren quieto: de él pueden verse unos cuantos árboles, un prado ralo y un cielo escaso y nublado. En primer plano, aunque sin impedir demasiado la visibilidad, las rayas del vidrio. En la segunda fotografía puede verse el mismo paisaje pero desde el tren en movimiento: el fotógrafo ha girado sobre su eje para registrar un paisaje que está a punto de dejar atrás. Ahora se percibe mejor el espacio: una planicie amplia, unos arbustos y unos árboles en la profundidad de campo. $\mathrm{Al}$ fondo, las montañas que crean el efecto de una lejanía considerable. La tercera foto figura una velocidad, tal vez, desquiciada. Ya no hay paisaje: apenas se puede ver una débil línea de horizonte, que divide una zona superior más clara (el cielo), de una inferior más oscura (la tierra), aunque no se puede asegurar que no sea solo una de las rayas del vidrio. Las rayas ocupan el primer plano y borronean todo lo demás, parecieran avanzar, violentas, hacia el fuera del vidrio.

Lo último que ve el niño es su propio rostro reflejado en los cristales del tren que se le aproxima. Entre esta mirada petrificada y la exterioridad sin significado de las fotografías que le siguen, lo que aparece es una forma de la contigüidad que tiene al espacio como campo de fuerzas e intensidades y eje de unos acontecimientos y unas relaciones que se han sustraído del significado. Un paisaje que se va borrando en la velocidad hiperbolizada de un tren y una mirada que solo se puede sostener a la distancia porque la clausura de esa distancia implica la apertura radical al misterio de la muerte. La estrategia de Ramal para hacer convivir la imagen fotográfica con el relato de un suicidio infantil tiene su fundamento en la forma de ser del espacio, donde nada significa, donde solo es posible ensayar, a destiempo, una búsqueda de pruebas de que lo que ya no existe, tuvo alguna vez toda la contundencia de lo real. 


\section{LO PROPIO, LO AJENO, EL MUNDO}

Para el protagonista todo es exterior, y sin embargo la narración acumula lentamente un resto de ausencias, algo que siempre falta, un mínimo desajuste entre el registro despojado de las condiciones del ramal y las imágenes fragmentadas del espejo de la casa de Maruri que inquieta la inercia decadente de los poblados y la apatía de sus pensamientos, y es en el cúmulo de esas ausencias que advienen que se quiebra la desconexión del personaje con el mundo, ese espacio de encuentro que figuraba ya la contigüidad del listado de características del buscarril con el plano vial marcado a mano y que habilita el recomienzo:

Al cabo de nueve años en el extranjero, comenzó a tener la sensación de que había olvidado algo. Lo que partió como un fogonazo se asentó como un desvelo. Por más que buscó el origen de la falta -creyó haber dejado una olla hirviendo, el gas licuado abierto, la llave de su casa en el extranjero en otra parte- la falta estaba más allá de él (123).

La vuelta del personaje a estas tierras (vuelta virtual, pues nunca había recorrido el ramal, vuelta una vez más tramada por los mecanismos impersonales del linaje familiar) actualiza esa articulación fatídica entre los espacios que se observan desde una distancia que el tono de la narración nunca traiciona y el pliegue más doloroso de la historia familiar interrumpida por el suicidio del hijo. En ese impreciso espacio liminar en que se encuentran el territorio y los afectos, las fotografías que siguen al relato del suicidio infantil aparecen como el lugar caótico que borronea tanto la mirada como aquello a lo que se dirige: figuran el progresivo borramiento de todo registro, de todo ordenamiento posible, postulan una imposibilidad radical, tanto de la palabra como de la imagen, para dar cuenta del mundo y sus devenires.

Tras el esperable fracaso de cualquier proyecto turístico capaz de salvar el ramal Talca-Constitución de su prolongada agonía, el protagonista vuelve a la casa de Maruri. Otra imagen cierra el ciclo de reencuentros: muertos su abuelo y su padre, muerto su hijo, ha quedado solo él para abrir las lucernas y dejar entrar la luz por la tarde. Los saqueos que sufrió la casa durante los años en que vivió en el extranjero dejaron intacto, sin embargo, el espejo del paragüero en que se reflejaban parcialmente sus antepasados cuando descansaban sobre el sillón de dos cuerpos ubicado 
frente al mueble. Ese reflejo incompleto y los rituales de la lucerna dieron nombre a los Bórquez que lo precedieron, es la taciturna comunión con los rincones de la casa de Maruri lo que les otorgó identidad. Una vez completada la vuelta del protagonista, abierto nuevamente el misterio de la muerte del hijo en el espacio indiferente en que tuvo lugar, espacio que permanece mudo y diáfano en su ausencia de justificaciones, finalmente el que viene de afuera es nombrado gracias a la imagen que lo restituye a la genealogía ineluctable que no deja de retornar a Maruri:

Deja sobre el escritorio las ideas para el proyecto que pretendía salvar al ramal. En la esquina del cuarto espera el madero con el que su abuelo, su padre y él abrieron y cerraron diariamente las celosías, permitiendo a la luz entrar y salir de la oscuridad. Desde el asiento de dos cuerpos donde dos generaciones se encogieron, León Bórquez contempla su reflejo (161). *

\section{Bibliografía}

Barthes, Roland. 2005 [1980]. La cámara lúcida. Nota sobre la fotografía. Buenos Aires: Paidós.

Bazin, André. 2008 [1945]. ¿Qué es el cine? Madrid: Rialp.

Benjamin, Walter. 2015a. "La obra de arte en la época de su reproductibilidad técnica". En Estética de la imagen. Buenos Aires: La Marca.

—. 2015b. "Breve historia de la fotografía". En Estética de la imagen. Buenos Aires: La Marca.

Deleuze, Gilles. 2005 [1985]. La imagen-tiempo. Buenos Aires: Paidós.

Jankélévitch, Vladimir. 2004. "Lo irrevocable". En Pensar la muerte. Buenos Aires: Fondo de Cultura Económica.

Krauss, Rosalind. 2002 [1990]. Lo fotográfico. Por una teoría de los desplazamientos. Barcelona: Gustavo Gili.

Pardo, José Luis. 1991. Sobre los espacios. Pintar, escribir, pensar. Barcelona: Ediciones del Serbal.

Rimsky, Cynthia. 2011. Ramal. Santiago de Chile: Fondo de Cultura Económica. Wenders, Wim. 1988. "El estado de las cosas". Medios revueltos. n. ${ }^{\circ}$ l (Madrid). Disponible en 〈http://www.4shared.com/web/preview/pdf/JT8dfroG〉. 